\title{
MONITORAMENTO DAS OSCILAÇÕES DO NÍVEL FREÁTICO NA ÁREA DO ANTIGO LIXÃO DE ROLÂNDIA - PR
}

\author{
Monielen Monara Betio ; Maurício Moreira dos Santos ${ }^{2}$
}

\begin{abstract}
Resumo - A área pesquisada refere-se ao antigo lixão de Rolândia. O local foi o destino da coleta pública de resíduos sólidos urbanos durante 60 anos. Os resíduos eram depositados diretamente ao solo expondo a massa de lixo a chuva e decomposição. A taxa de infiltração do percolado através da zona não saturada do solo pode influenciar na contaminação de aquíferos, produzindo uma pluma cujo fluxo é a base dos rios. Tem-se como objetivo, descrever o histórico e a situação atual do local; monitorar e interpretar a dinâmica hidrogeológica do aquífero freático frente às taxas contínuas de recarga por precipitação. O monitoramento dos níveis de água subterrânea foi realizado quinzenalmente, no período de Agosto a Novembro de 2014, em três poços (P1, P2 e P3) instalados entre o talude de massa aterrada e o ribeirão Vermelho. Os dados mostraram que a elevação do nível freático possui uma rápida resposta em relação à recarga d'água. $\mathrm{Na}$ ocorrência de chuvas moderadas por um longo período, a resposta do nível freático permanece constante, por outro lado, com chuvas intermitentes em um curto período, a resposta do nível não é rápido devido à saturação total dos poros formando o escoamento superficial.
\end{abstract}

\begin{abstract}
The research area is the old garbage dump of Rolândia city. The local was destination of public collection of municipal solid waste during 60 years. The waste was deposited directly into the ground exposing the trash mass the rain and decomposition. The infiltration rate of percolated through vadose zone may influence contamination of aquifers, producing a plume which flow is the basis of the rivers. It has been the objective, to describe the history and current local situation; to monitor and to interpret the dynamic hydrogeological of aquifer through continuous rates for recharge rainfall. The monitoring of groundwater levels it was performed fortnightly, in the period of August and November 2014, in three wells (P1, P2 and P3) installed between mass buried slope and Red brook. The data show that higher water table level has a quick answer about water recharge. In case of moderate rain for a long period, the answer of water table level remain constant, on the other hand, with intermittent rain in a short period, the answer of water table level is not quick because full saturation of the soil pores forming the runoff.
\end{abstract}

Palavras-Chave - Precipitação; Percolado; Contaminação;

\footnotetext{
${ }^{1}$ Graduada em Engenharia Ambiental pela Universidade Tecnológica Federal do Paraná - campus Londrina, monielenmonara@ gmail.com

${ }^{2}$ Professor Dr.da Universidade Tecnológica Federal do Paraná - Campus Londrina, Av. dos Pioneiros, 3131, CEP 86036-370 - Londrina - PR -

Brasil, mmsantos@utfpr.edu.br
} 


\section{1 - INTRODUÇÃO}

O lixão é caracterizado por Fadini (2001) como uma mera disposição do lixo a céu aberto, sem nenhum critério sanitário de proteção ao ambiente, que possibilita o pleno acesso de vetores de doenças como moscas, mosquitos, baratas e ratos ao lixo, tendo na recepção o homem no posto de separador de lixo, à espera da matéria-prima que possibilita a sua sobrevivência, convivendo com urubus, insetos, ratos e suscetíveis a doenças que através dele voltarão depois para os centros urbanos.

Os resíduos sólidos urbanos acumulados continuamente em lixões ou aterros não são, contudo, inativos. Essa mistura de uma grande variedade química, sob a influência de agentes naturais, chuva e microrganismo, é objeto de evoluções complexas, constituídas pela superposição de mecanismos físicos, químicos e biológicos. Além da dissolução dos elementos minerais e do carreamento pela água de percolação das finas partículas e do material solúvel, o principal responsável pela degradação dos resíduos é a bioconversão da matéria orgânica em formas solúveis e gasosas. O conjunto desses fenômenos dá origem aos vetores da poluição em aterros e lixões: o biogás e os lixiviados (CASTILHOS JR, 2003).

Os lixiviados são definidos como os líquidos provenientes de três fontes principais: umidade natural dos resíduos sólidos; água de constituição dos diferentes materiais que sobram durante o processo de decomposição; e líquido proveniente de materiais orgânicos pelas enzimas expelidas pelas bactérias. O movimento dos líquidos percolados no solo ocorre verticalmente na zona não saturada (CASTILHOS JR, 2003).

O monitoramento de nível do aquífero livre e das taxas de precipitações nessas regiões de grande passivo ambiental é de suma importância, pois a migração do percolado através da zona não saturada do solo pode influenciar no favorecimento da contaminação das águas subterrâneas, produzindo extensa pluma de contaminação que tem como direção o fluxo de base dos mananciais superficiais.

\section{2 - OBJETIVOS}

Os objetivos deste trabalho consistem em descrever e avaliar o histórico e a situação atual do antigo lixão de Rolândia-PR, bem como monitorar e interpretar do ponto de vista hidrogeológico a dinâmica de flutuação do aquífero livre, localizado à jusante do antigo lixão de Rolândia - PR, frente às taxas contínuas de recarga por precipitação. 


\section{3 - CARACTERIZAÇÃo DA ÁREA DE ESTUDO}

A área de pesquisa localiza-se no perímetro urbano da cidade de Rolândia-PR, mais precisamente na porção norte do município. O local de estudo foi durante 60 anos o destino final da coleta pública de resíduos sólidos urbanos, antes de sua desativação em abril de 2002. Possui área total de $65.318 \mathrm{~m}^{2}$, área efetiva com lixo de cerca de $30.318 \mathrm{~m}^{2}$ e com volume estimado de 180.000 $\mathrm{m}^{3}$ de lixo depositado. Localizada na bacia hidrográfica do ribeirão Vermelho, na vertente esquerda se distancia em $2 \mathrm{~km}$ da sua nascente (Figura 1).
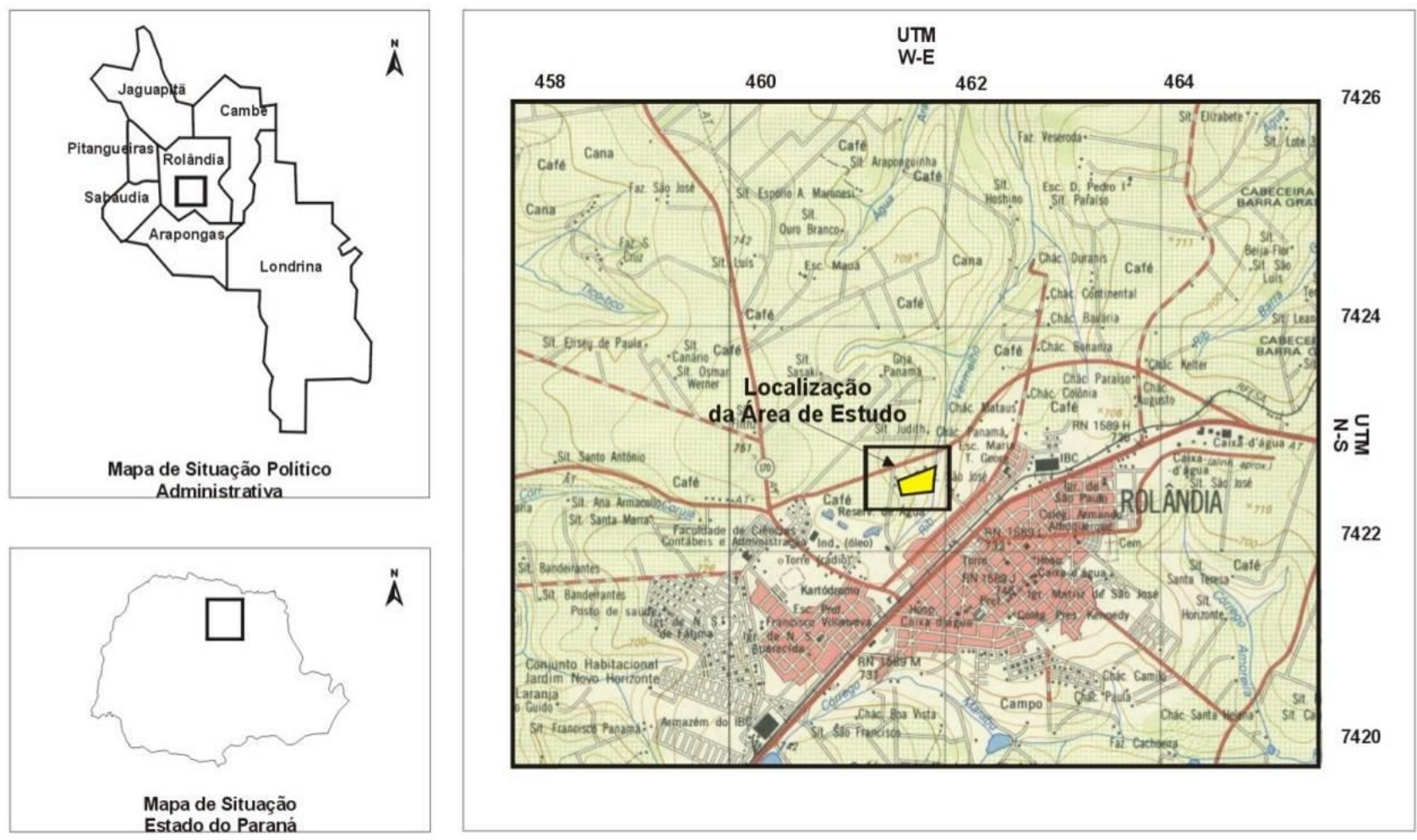

Figura 1. Mapa de localização do antigo lixão de Rolândia - PR. Fonte: Santos (2003).

O estado do Paraná possui influência macroclimática de predominância subtropical, na zona em questão, segundo Yoshiura (2006), destaca-se o subtipo climático Cfa (Subtropical Úmido Mesotérmico) caracterizada pela temperatura moderada, com chuvas em todas as estações do ano, podendo ocorrer um período de seca durante o inverno, quando também, podem ocorrer geadas. O período mais chuvoso concentra-se nos meses de dezembro, janeiro e fevereiro, com média de 500 mm a $600 \mathrm{~mm}$, e o período com o menos índice pluviométrico é junho, julho e agosto, variando de $175 \mathrm{~mm}$ a $250 \mathrm{~mm}$.

O norte paranaense, no qual envolve a área de estudo, possui evolução geomorfológica disposta por toda a bacia sedimentar do Paraná, inserida no Terceiro Planalto Paranaense, onde se desenvolve a estrutura geomorfológica das Cuestas Areníticas Basálticas (SANTOS, 2003). 
Na região do antigo lixão de Rolândia o relevo é ondulado a suavemente ondulado, com vales pouco entalhados e vertentes longas e com baixa declividade (Figura 2). Com cotas topográficas variando entre 660 e 720 metros acima do nível do mar, a conformação topográfica da área de estudo possui inclinação suave no sentido W-E, obedecendo à drenagem do Ribeirão Vermelho, cujo sentido SW-NE obedece por sua vez, a drenagem do rio Paranapanema, do qual é afluente direto, constituindo ambos parte da Bacia do Rio Paraná (SANTOS, 2003).

O Latossolo Vermelho e o Nitossolo são as principais formações pedológicas encontradas na região do município. De modo geral, os solos na região em questão apresentam-se normalmente profundos, pouco suscetíveis à erosão. Suas características morfológicas apresentam poucas variações, fazendo com que os diversos horizontes se apresentem poucos individualizados e difusos. O Latossolo Vermelho é formado quase que completamente da rocha mãe (basalto) e constituído de grandes quantidades de ferro hidratado, dando-lhe a característica de coloração bastante escura (SANTOS, 2003).

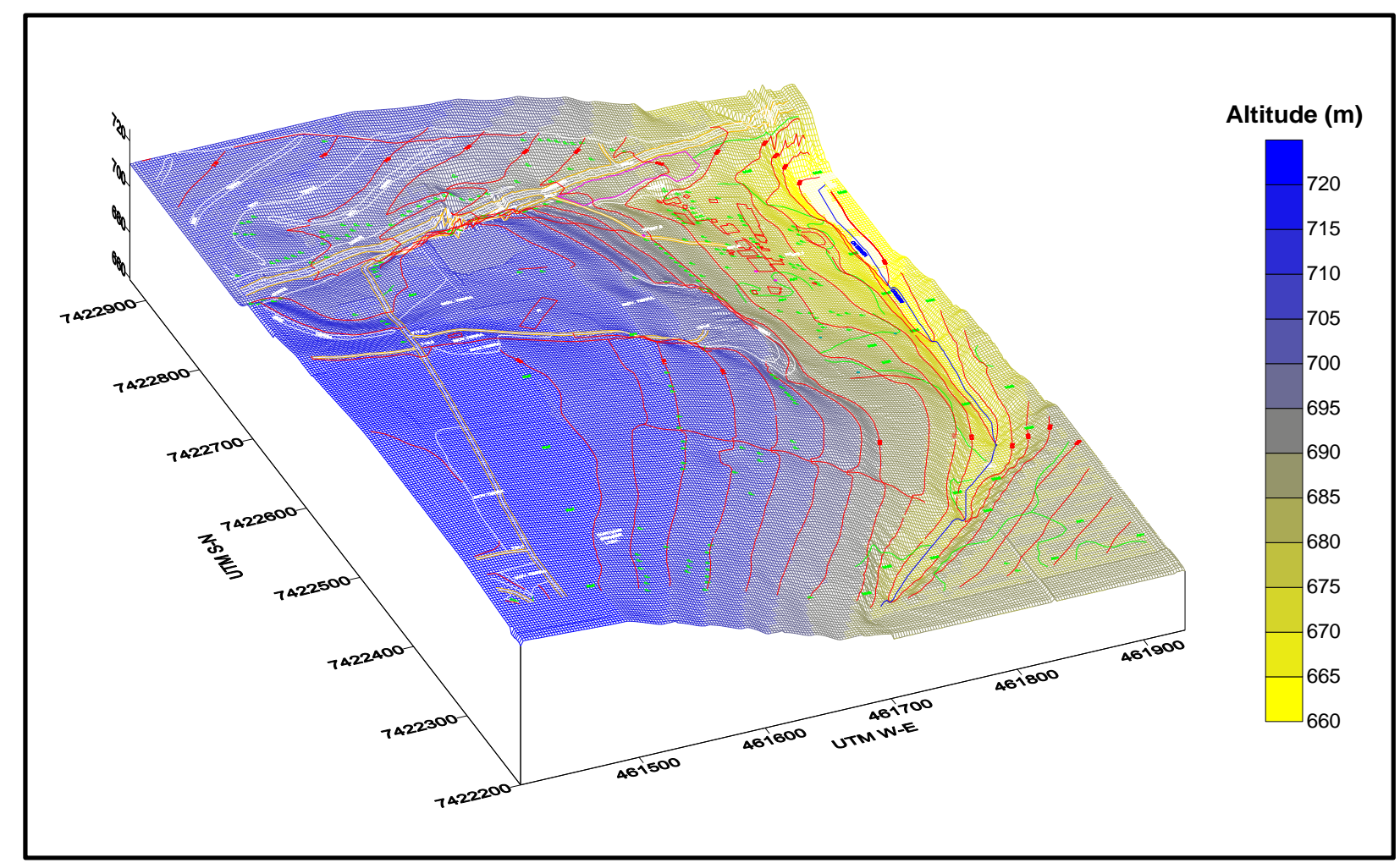

Figura 2. Bloco diagrama evidenciando a conformação topográfica da área de estudo. Fonte: Santos (2003).

A área de estudo está inserida geologicamente nos limites da Bacia Sedimentar do Paraná, assentada sobre os basaltos pertencentes a Formação Serra Geral, que têm origens do intenso vulcanismo fissural que atingiu a bacia, constituindo ampla província magmática, definindo no Fanerozóico a maior manifestação ígnea não-oceânica e uma importante contribuição à geração da 
crosta ocidental do planeta. Esse evento traduziu-se na bacia, como uma espessa cobertura de lavas, uma intricada rede de diques contando a completa seção sedimentar.

Segundo Milani (1997) a Formação Serra Geral, de maneira generalizada, é composta principalmente por rochas vulcânicas básicas, toleíticas e andesitos basálticos ocorrendo subordinadas quantidades de riodacitos e riolitos, de textura afanítica, coloração cinza e negra. Os topos dos derrames é geralmente amigdaloidal, apresentando grande desenvolvimento de juntas verticais e horizontais com intrusões alcalinas e de pequenas lentes de arenito (MILANI, 1997).

\section{1 - Hidrogeologia}

$\mathrm{Na}$ área estudada existem duas formas de ocorrência de água subterrânea: o aquífero freático e o sistema aquífero Serra Geral (CELLIGOI et al., 2001).

$\mathrm{O}$ aquífero freático tem características essenciais de aquífero livre ou não confinado. Visto que possui camadas de solo e rocha alterada e é formado por sedimentos argilosos, constituindo-se em um meio poroso heterogêneo, geralmente pouco espesso e com baixa profundidade do nível saturado. Dessa forma, a recarga se dá diretamente a partir de águas pluviais nas áreas mais elevadas topograficamente, aumentando os riscos em relação à contaminação ou poluição das águas subterrâneas (SANTOS, 2003).

A superfície freática do local acompanha de uma forma geral a superfície do terreno evidenciada. A Figura 3 demonstra uma conformação topográfica cuja área de recarga local do aquífero freático se encontra nas porções mais elevadas do terreno, sendo a área de descarga localizada nas partes mais rebaixadas do relevo, em direção à calha do ribeirão Vermelho (SANTOS, 2003) 


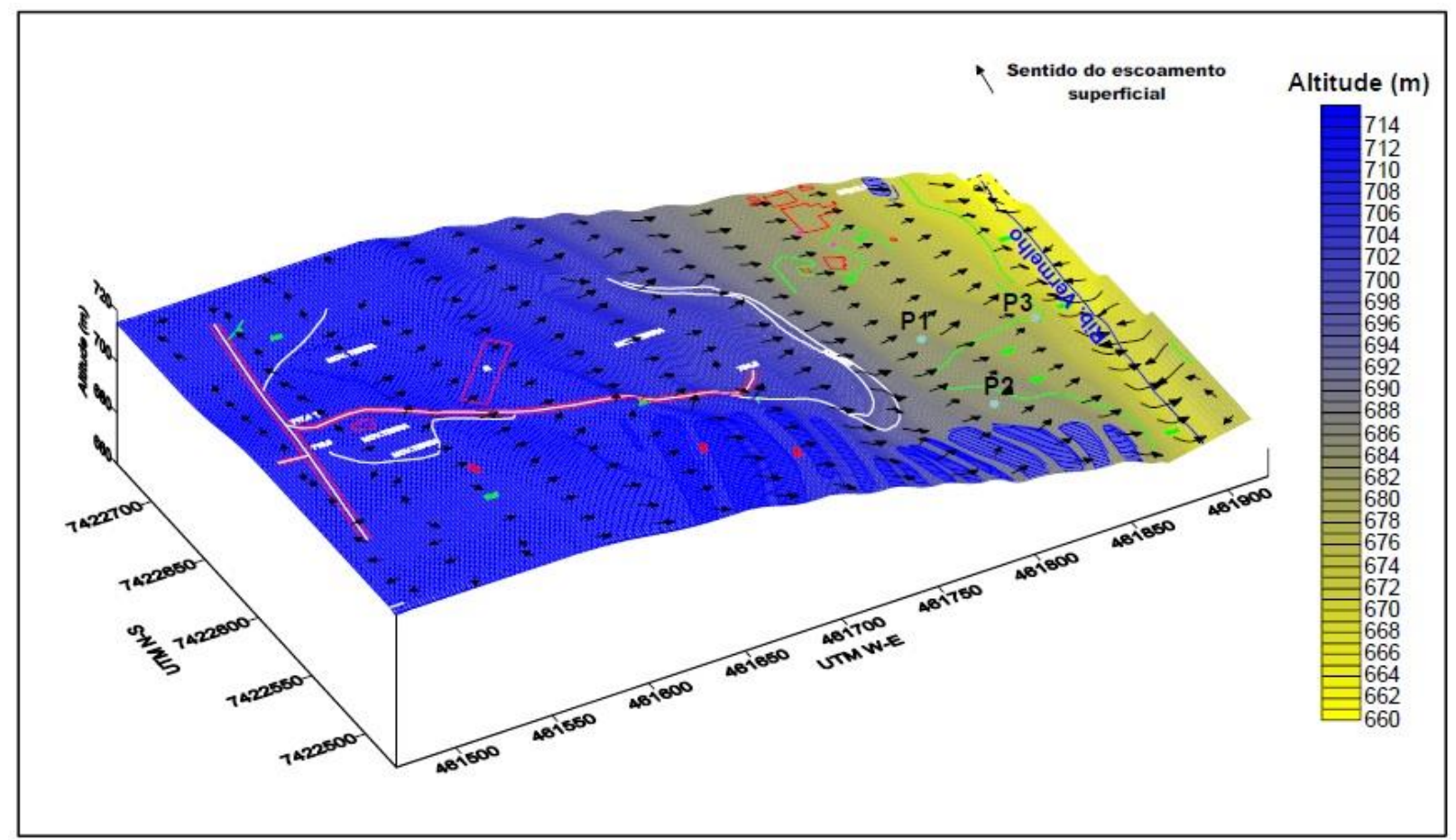

Figura 3. Bloco diagrama evidenciando a conformação topográfica, área de recarga e descarga do aquífero da área estudada. Fonte: Santos (2003).

\section{4 - METODOLOGIA}

\section{1 - Monitoramento do Nível Freático}

O monitoramento dos níveis de água subterrânea foi realizado quinzenalmente a partir de três poços instalados na área de estudo durante o processo de encerramento do lixão. Tais poços foram

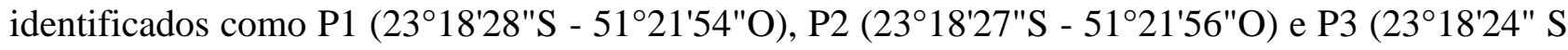
- 51 ${ }^{\circ} 22^{\prime} 07^{\prime \prime O}$ ) e se encontram a jusante do antigo lixão, entre o talude da massa de lixo aterrada e o ribeirão Vermelho (Figura 4).

O monitoramento do nível freático tem como objetivo fornecer dados sobre as condições de equilíbrio do aquífero freático em termos de evolução temporal da resposta dos níveis piezométricos frente aos volumes de recarga/infiltração direta nos períodos de chuva que ocorreram ao longo dos 4 meses de pesquisa, ou seja, durante os meses de Agosto a Novembro de 2014. 


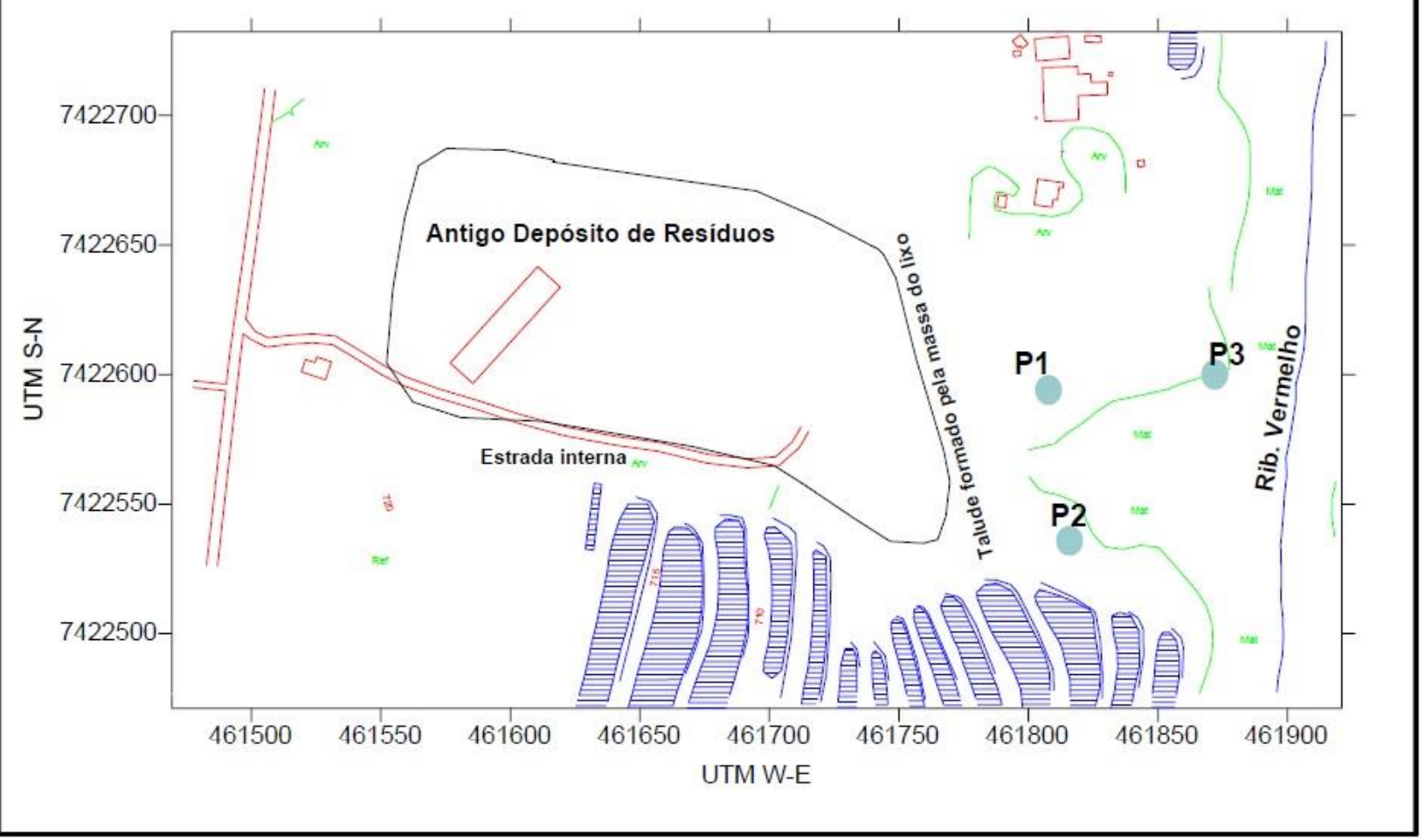

Figura 4. Mapa de localização dos poços de monitoramento. Fonte: Santos (2003).

Segundo Santos (2003), os poços foram perfurados com base em critérios técnicos. Teve como empresa executora a GEOPOÇOS - Poços artesianos, cuja sede é localizada em Rolândia PR. O equipamento utilizado foi a Sonda Perfuratriz Percurssora que perfurou utilizando método rotativo. A perfuração adotada foi de Ø8”, recomendada para solo com rocha alterada. Os revestimentos utilizados foram: Tubos filtros de PVC Geomecânico Ø4"; e Tubos lisos de PVC Geomecânico Ø4". Como complementação foi preenchido o espaço anelar com pré-filtro de granulometria entre 1 e $2 \mathrm{~mm}$, com selo sanitário feito com bentonita e cimento na porção superior e tubo de boca de PVC com Ø8", conforme ilustra a Figura 5. 


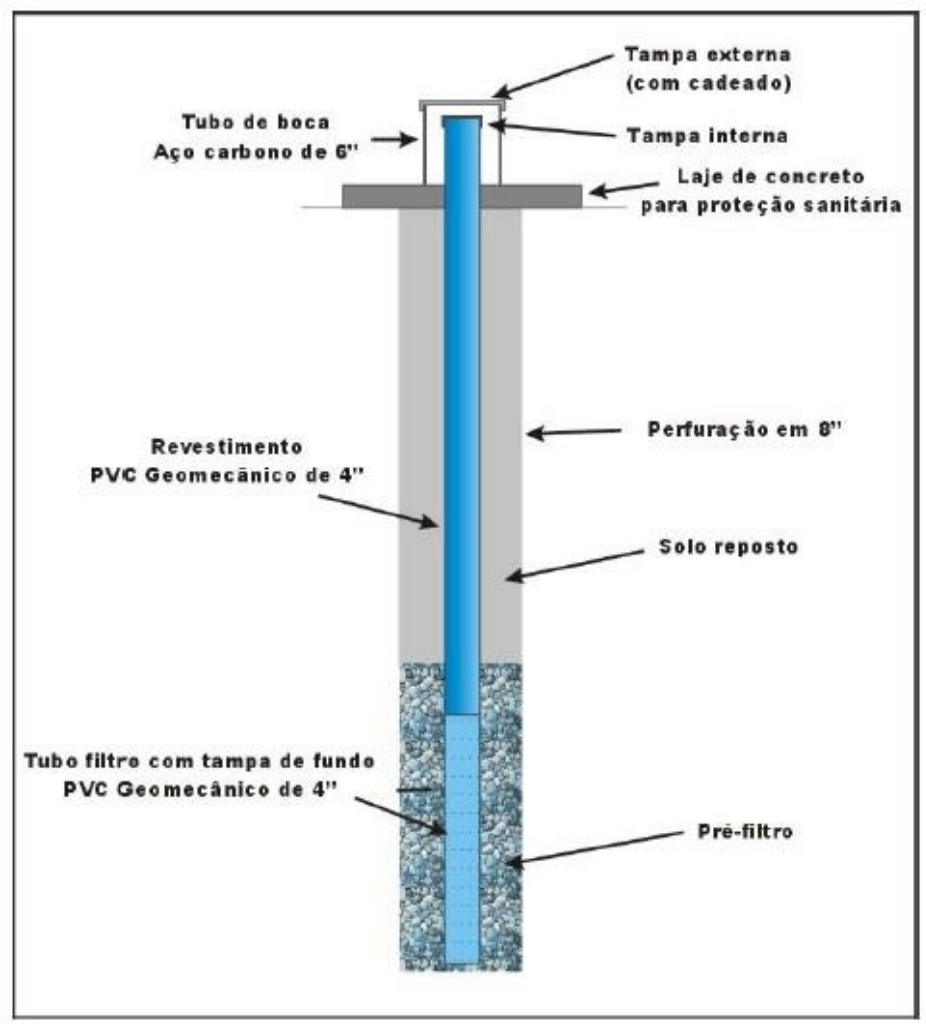

Figura 5. Esquema de construção dos poços de monitoramento. Fonte: Santos (2003).

A profundidade dos poços e a profundidade do tubo filtrante estão especificados na Tabela 1 a seguir.

Tabela 1- Especificações dos poços de monitoramento, profundidade total e do filtro.

\begin{tabular}{ccc} 
Poço & Profundidade $(\mathbf{m})$ & Filtro $(\mathbf{m})$ \\
\hline P1 & 14,00 & 2,00 \\
P2 & 11,50 & 4,00 \\
P3 & 7,50 & 4,00 \\
\hline
\end{tabular}

Fonte: Geopoços - poços artesianos LTDA. Santos (2003).

Para o acompanhamento regular da evolução dos níveis estáticos subterrâneos dos poços de monitoramento utilizou-se um medidor de nível d'água elétrico modelo: HSNA-100, da HS Hidrosuprimentos (Figura 6). Tal equipamento possui uma sonda com um sensor na ponta de uma fita resistente de nylon graduada em milímetros, que ao tocar a água fecha um circuito ativando um sinal sonoro e luminoso alimentado por baterias de 9 volts. 


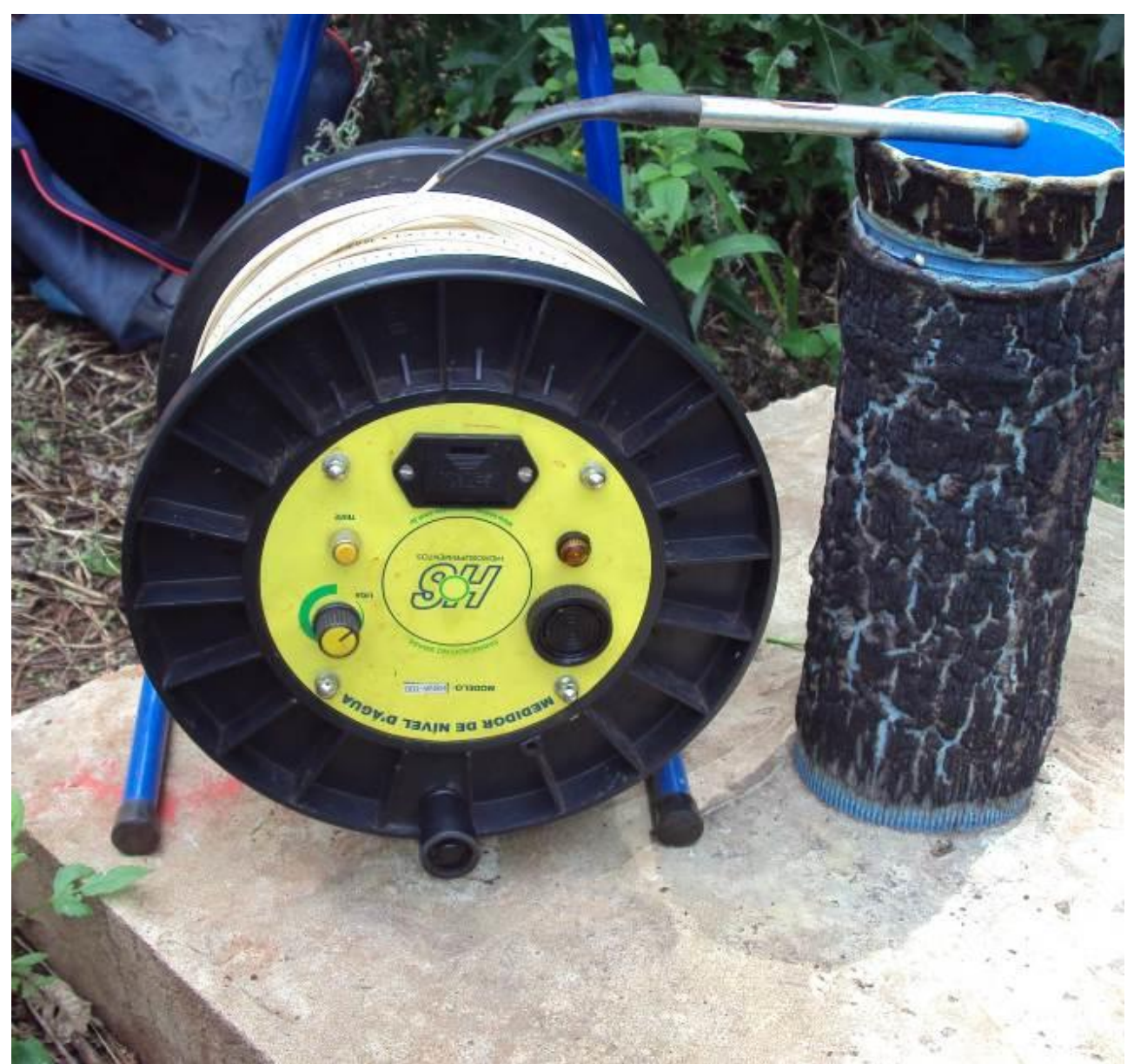

Figura 6. Medidor de nível d’água. Fonte: Autor (2014).

As medições do nível de água subterrânea foram efetuadas durante o período de Agosto a Novembro de 2014 com frequência média quinzenal, totalizando 7 medições. Nas visitas de campo era feito, primeiramente, a inspeção, checagem e verificação dos equipamentos, a fim de garantir a imediata atualização das informações e o perfeito funcionamento das estações de controle, seguido de coleta dos dados e posterior cálculo da oscilação média do nível freático.

\section{2 - Recarga Aquífera por precipitação - Parâmetro Quantitativo}

O regime pluviométrico é um dos principais fatores que influenciem na taxa de degradação dos resíduos e a produção do percolado, e a consequente poluição dos aquíferos adjacentes aos lixões. Além disso, as chuvas influenciam diretamente o comportamento do nível freático local associado ao volume de infiltração que efetivamente chega ao lençol freático em forma de recarga aquífera (SILVA, 2014).

A partir dos dados dos níveis freáticos e dos valores diários de precipitação fornecidos pela estação meteorológica do Instituto Agronômico do Paraná - IAPAR (2014) localizado na Rodovia 
Celso Garcia Cid km 375, em Londrina - PR, com coordenadas 2321'43”S e 519'59”W, foi realizado, para melhor interpretação, um cruzamento destes dados utilizando para análise planilhas de cálculos disponibilizadas no programa Microsoft Office Excel 2007 com a finalidade de verificar o volume total de chuvas e avaliar os aspectos relacionados à recarga do aquífero freático local a partir do monitoramento da variação dos níveis na área em estudo.

Estes resultados deram continuidade os resultados obtidos por Silva (2014), em seu trabalho de conclusão de curso, no período de Agosto de 2013 a Julho de 2014.

\section{5 - RESULTADOS E DISCUSSÕES}

\section{1 - Antigo lixão de Rolândia - PR: Histórico e Situação Atual}

Os resíduos domésticos, coletados pela Prefeitura Municipal de Rolândia, tiveram como destinação final até abril do ano de 2002, um vazadouro a céu aberto, ou mais popularmente conhecido como lixão (SANTOS, 2003).

O funcionamento do lixão teve início nos anos 40, até que foi decretado o seu encerramento pela prefeitura municipal após 60 anos de funcionamento, quando a área ultrapassou o limite máximo de saturação para recebimento dos resíduos urbanos e também pela proximidade de conjuntos habitacionais, provocados pela expansão urbana do município (MELO, 1999).

O manejo dos resíduos sólidos urbanos no local, anterior ao seu encerramento, era totalmente equivocado em relação aos critérios técnicos ambientais e sanitários para a adequada destinação e tratamento final de resíduos. Segundo Melo (1999), o lixo urbano de Rolândia era disposto diretamente ao solo natural, não havendo a cobertura constante do lixo por material inerte após a conclusão de cada jornada de trabalho, possibilitando assim a ação de catadores de lixo no local, conforme evidencia a Figura 7. 


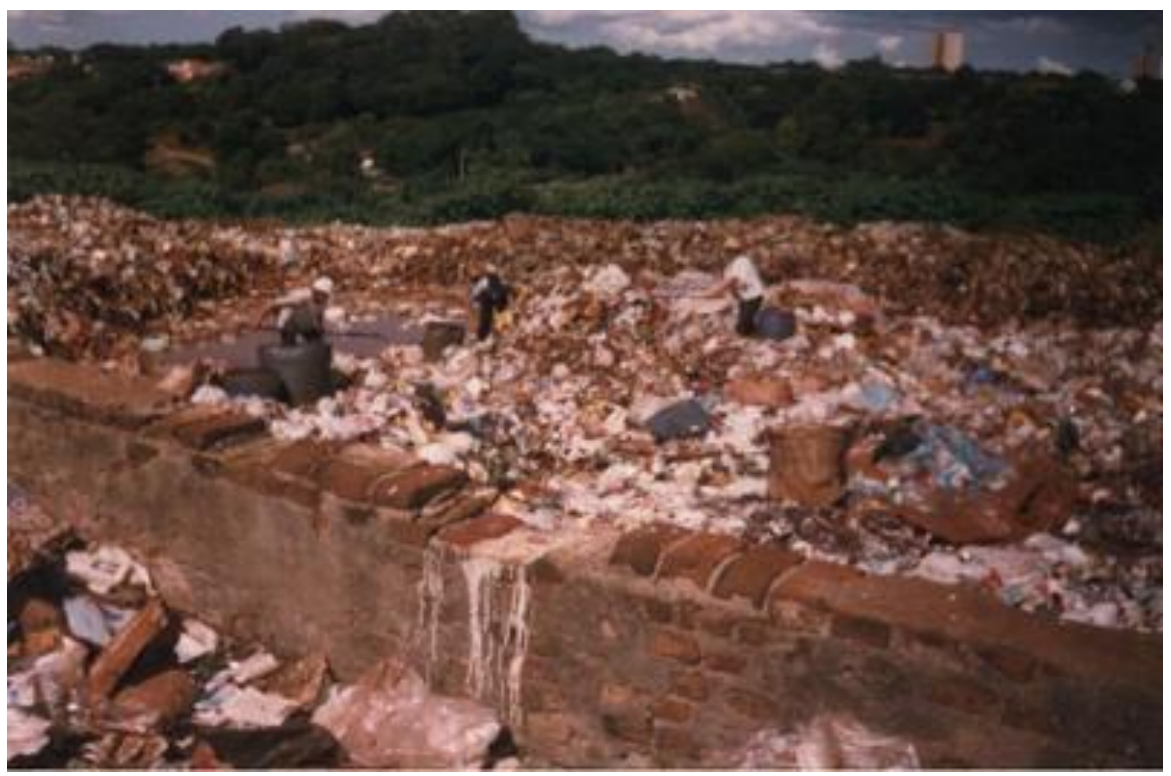

Figura 7 - Resíduos Sólidos depositados diretamente no solo e a presença de catadores de lixo no local. Fonte: Melo (1999).

Na tentativa de reduzir o volume de resíduos, Melo (1999) afirma que os caminhões da coleta municipal despejavam os resíduos e estes eram compactados superficialmente por uma esteira, ou por vezes empurrados vertente abaixo, conforme ilustra a Figura 8.

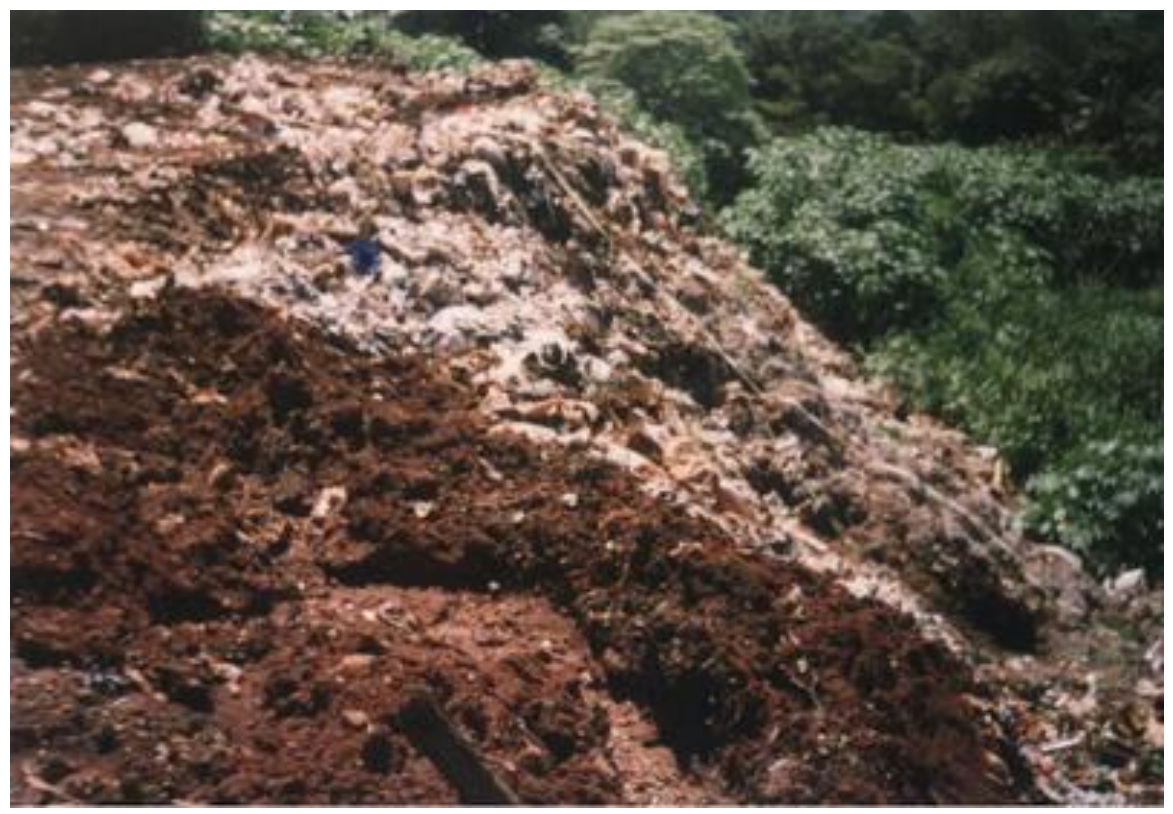

Figura 8 - Talude formado pelo despejo incorreto dos caminhões de coleta municipal e esteira de compactação. Fonte: Melo (1999).

Melo (1999) afirma ainda que o lixão recebia os mais diversos tipos de resíduos, principalmente matéria orgânica proveniente de coleta domiciliar, que após a sua disposição ficavam expostos completamente às condições meteorológicas, o que facilitava a combustão espontânea, a decomposição do lixo e a produção de percolado no qual não recebia qualquer tipo de 
tratamento, somada a inexistência de drenos condutores de chorume, água superficial ou gases (Figura 9).

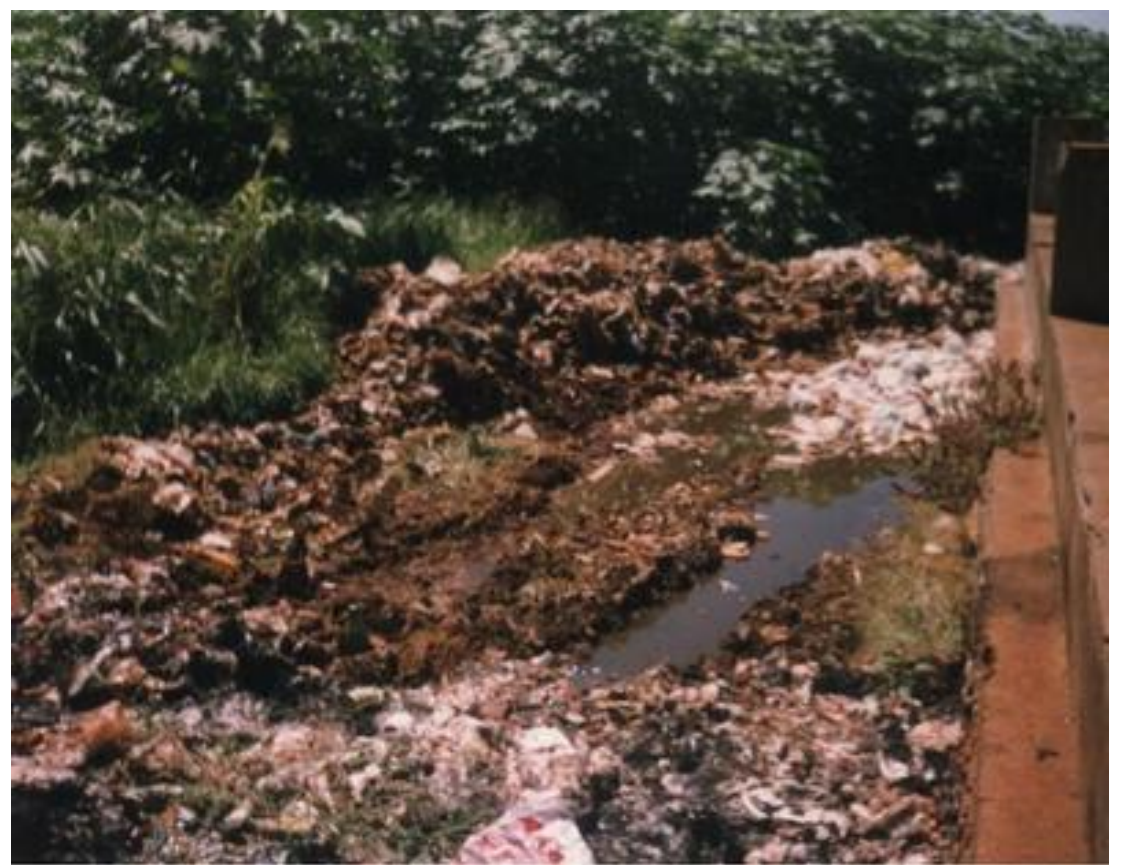

Figura 9 - Ausência de drenos condutores de chorume, águas superficiais e gases. Fonte: Melo (1999).

Hoje, a antiga área de destinação final dos resíduos sólidos urbanos do município de Rolândia encontra-se em total estado de abandono. Após o encerramento do lixão não ocorreu no local a recuperação da área degradada, a fim de minimizar os impactos ambientais e sanitários, bem como a melhoria dos aspectos paisagísticos.

O local onde eram depositados os resíduos foi totalmente coberto por solo, e o aspecto físico aparenta um talude de cerca de 8 a 10 metros de altura formada pela massa de lixo disposta durante os 60 anos de funcionamento do lixão (SANTOS, 2003). Não é possível observar as diversas camadas de resíduos compactadas, pois a área está totalmente ocupada por vegetação secundária (Figura 10). 


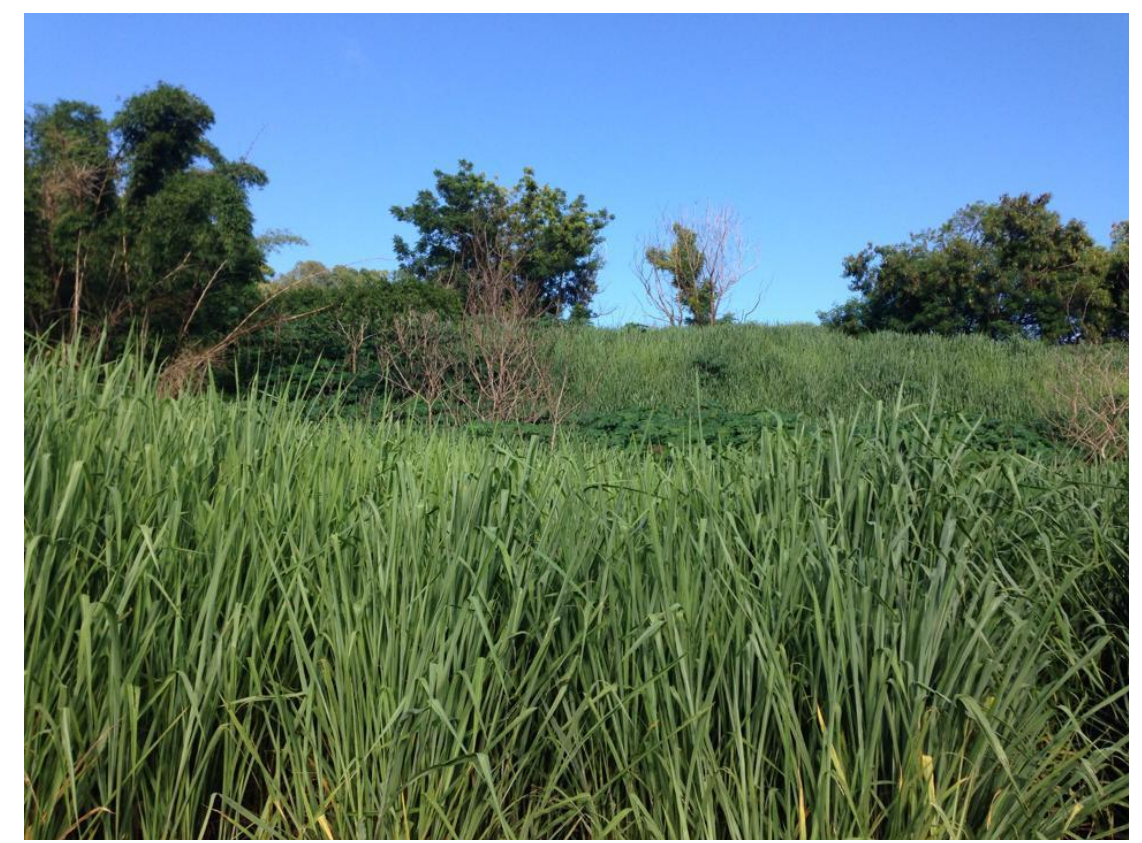

Figura 10 - Situação atual da área do antigo lixão. Fonte: Silva (2014).

No entanto, a massa de resíduos recoberta está em contínuo processo de decomposição anaeróbia, a qual é lenta e perdurará ao longo dos anos, gerando percolados e condicionando ainda sérios riscos ao meio ambiente e a saúde pública (SANTOS, 2003).

\section{2 - Oscilação do Nível Freático e a Precipitação Pluviométrica}

Os valores medidos através do medidor de nível estão apresentados na Tabela 2, de acordo com as datas de realização. No entanto, vale ressaltar que valores altos equivalem a rebaixamento no nível freático e valores baixos equivalem a aumento no nível com relação a profundidade. Também está apresentada a somatória das precipitações diárias obtidas pela estação meteorológica do Instituto Agronômico do Paraná - IAPAR (2014).

Tabela 2 - Data de realização das medidas dos níveis freáticos e seus valores, além da somatória das precipitações dos dias anteriores.

\begin{tabular}{ccccc}
\hline $\begin{array}{c}\text { Data da } \\
\text { medição }\end{array}$ & $\mathbf{P 1}$ & $\mathbf{P 2}$ & $\mathbf{P 3}$ & $\begin{array}{c}\text { Somatória da } \\
\text { precipitação } \\
\text { (mm) }\end{array}$ \\
\hline $16 / 07 / 2014$ & 5,42 & 4,91 & 4,76 & 28,90 \\
$09 / 08 / 2014$ & 5,39 & 4,83 & 4,74 & 55,50 \\
$30 / 08 / 2014$ & 5,42 & 4,89 & 4,78 & 30,30 \\
$09 / 09 / 2014$ & 5,54 & 4,98 & 4,85 & 31,80 \\
$27 / 09 / 2014$ & 5,38 & 4,93 & 4,38 & 133,80 \\
$04 / 10 / 2014$ & 5,52 & 4,69 & 4,69 & 14,00 \\
$29 / 10 / 2014$ & 5,66 & 5,09 & 4,86 & 6,30 \\
$10 / 11 / 2014$ & 5,73 & 5,16 & 4,90 & 36,00 \\
\hline
\end{tabular}


O valor da somatória da precipitação da primeira data desta pesquisa (16/07/2014) foi somado com relação a última data de medição do trabalho de Silva (2014), de forma que este trabalho dê continuidade a sua pesquisa.

A Figura 11 exibe o gráfico das oscilações do nível freático confrontados com o somatório da precipitação durante a realização do monitoramento na área de estudo durante todo o período estudado por Silva (2014).

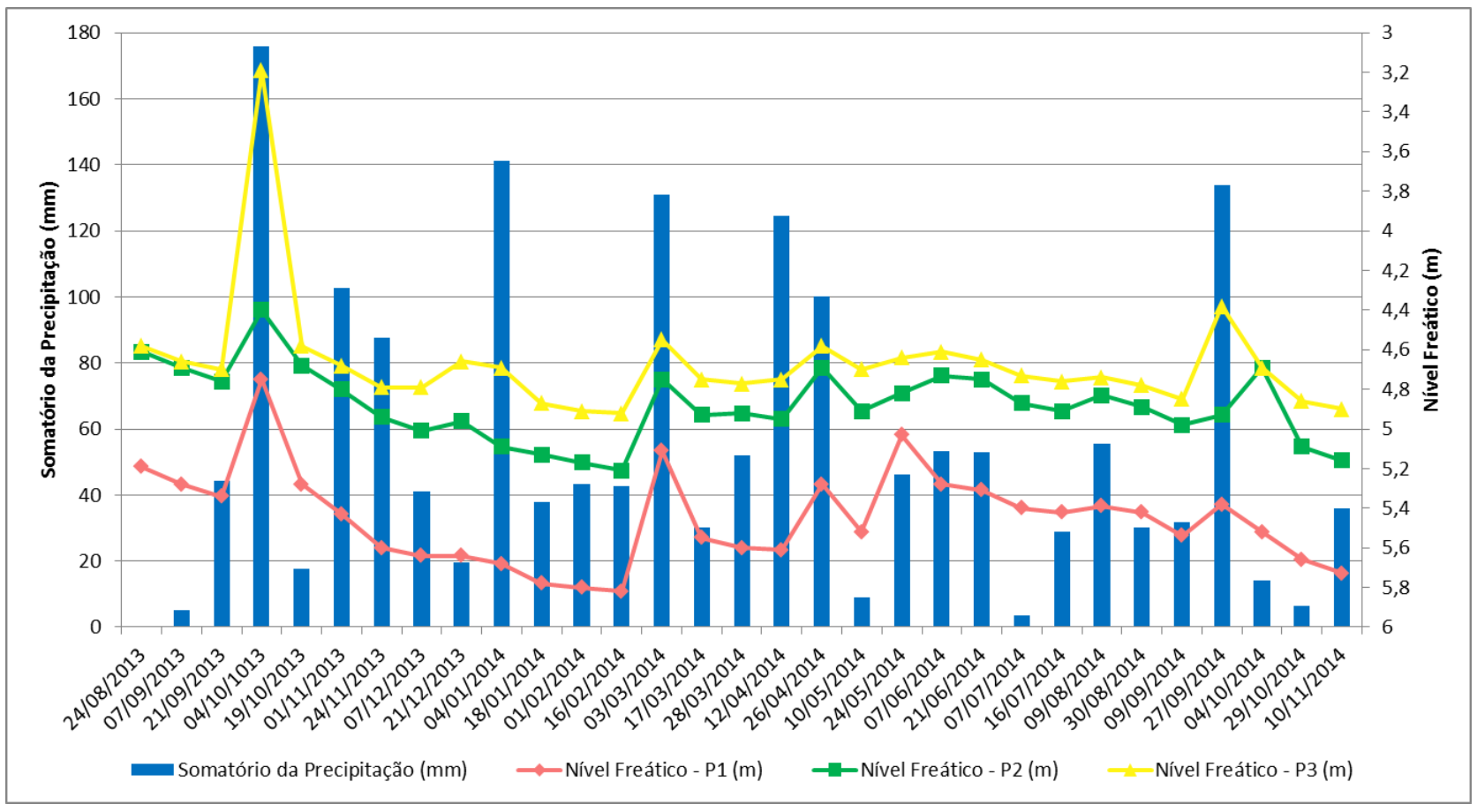

Figura 11. Gráfico exibindo a correlação dos níveis d'água subterrânea com o somatório das precipitações diárias. Fonte: Adaptado de Silva (2014).

De acordo com a análise da Figura 11, é possível verificar que a partir do somatório da precipitação do intervalo de aproximadamente 15 dias anteriores ao dia de medição a resposta da variação da elevação do nível sempre foi rápido comparado ao volume de precipitação.

Silva (2014) em seu trabalho com a permeabilidade hidráulica neste mesmo local notou que a velocidade de percolação vertical da água no solo é de $1,85 \mathrm{~m} \cdot \mathrm{d}^{-1}$, classificou-se, então, este solo como do tipo areias finas siltosas e argilosas ou siltes argilosos, tendo assim, grau de permeabilidade baixa.

De maneira geral, assim que ocorriam precipitações entre os intervalos de medida, em poucos dias já se notava a influência da chuva e recarga na elevação do nível freático, principalmente com chuvas acima de $100 \mathrm{~mm}$.

Observando a Figura 11 percebe-se que nos momentos em que ocorrem chuvas moderadas por um longo período de tempo, como por exemplo do dia 21 de Setembro de 2013 até 07 de Março de 2014 e 10 de maio de 2014 até 09 de Setembro de 2014, a resposta do nível freático mostrou-se 
mais constante. Já em dias que houve intensa precipitação em períodos curtos, como por exemplo 27 de Setembro de 2014, a resposta do nível não apresentou-se tão rápida se comparado ao volume total de chuva.

Fetter (2001) explica que a infiltração que promove a recarga do aquífero só acorre após o momento em que os espaços vazios da camada superior do solo forem preenchidos. Parte desta água acumulada na primeira camada do solo estará retida nos interstícios dos poros e será responsável por nutrir a vegetação que se estabilizar no local. Após o total preenchimento dos espaços vazios, a água irá infiltrar nas camadas mais profundas promovendo a recarga do aquífero.

Porém, o excesso de precipitação posterior a uma chuva intensa em um curto período de tempo não será capaz de infiltrar devido à saturação total dos poros do solo e sua limitada capacidade de transmissão de água, dessa forma, o escoamento superficial é formado, não recarregando os aquíferos.

Vale ressaltar que existem fatores climáticos, fisiográficos (relevos de bacia) e antrópicos (uso do solo e obras hidráulicas), que de maneira geral, podem exercem influência sobre o escoamento superficial (SILVA, 2014).

\section{6 - CONCLUSÃO}

Este estudo de caso mostra que o simples aterramento e abandono, há mais de dez anos, do antigo lixão de Rolândia - PR, não foi suficiente para sua recuperação natural. Pelo contrário, abandoná-lo, sem um monitoramento adequado dos aspectos hidrogeológicos e da qualidade natural do solo e dos recursos hídricos, provoca o descontrole dos impactos ambientais típicos de áreas e lixões que continuarão a se propagar por um longo período. Observa-se a partir do estudo histórico evolutivo, que desde a desativação não houve qualquer obra técnica para prevenção dos impactos provocados pela disposição inadequada dos resíduos sólidos.

Portanto, tendo em vista o tempo decorrido desde a data de desativação do lixão, está comprovado que o mesmo não possui autossuficiência para se regenerar naturalmente. Assim, vale a pena enfatizar a necessidade de estudos e ações ambientais para remediação e recuperação desta área degradada.

Correlacionando as características do meio poroso com os níveis de precipitação diária no local, no período total de estudo (24 Agosto 2013 - 10 Novembro 2014), mostrou que a elevação do aquífero livre possui uma rápida resposta em relação a recarga d'água. Na ocorrência de chuvas moderadas por um longo período, a resposta do nível freático permanece constante, por outro lado, com chuvas intermitentes em um curto período, a resposta do nível é retardada devido à saturação 
total dos poros formando o escoamento superficial, sendo liberado posteriormente, mas com menor influência na elevação do nível.

Nesse sentido, na ocorrência de chuvas moderadas por um longo período, o chorume tem sua migração favorecida através da zona não saturada, podendo atingir a zona saturada, portanto, transportando produtos contaminantes através de correntes advectivas ao longo de seu deslocamento, gerando assim uma pluma poluente cujo fluxo alcançará a base de rios, ribeirões, córregos e lagoas.

\section{7 - REFERÊNCIAS BIBLIOGRÁFICAS}

CASTILHO JR. Armando B. de. RESÍDUOS SÓLIDOS URBANOS: ATERRO

SUSTENTÁ VEL PARA MUNICPIOS DE PEQUENO PORTE. PROSAB 3. Capítulo 2:

Principais Processos de Degradação de Resíduos Sólidos Urbanos. Florianópolis, Rio de Janeiro: ABES, RiMa, 2003;

CELLIGOI, A.; SANTOS, M. M.; VIANA, T. R. Análise e interpretação do gradiente hidráulico do aqüífero freático em uma área na região sul de Londrina-PR. Geografia - Revista do Departamento de Geociências. UEL, v. 10, n. 1, p. 79-87, 2001;

FADINI, Pedro S.; FADINI, Almerinda A. B. Lixo: desafios e compromissos. Maio, 2001. Disponível em: <http://www.ceset.unicamp.br/ mariaacm/ST114/lixo.pdf>. Acesso em: 22 de fevereiro de 2014;

FETTER, Charles. W. Applied Hydrogeology, 4. ed., New Jersey: Prentice Hall, 2001;

IAPAR. INSTITUTO AGRONÔMICO DO PARANÁ. Agrometeorologia - Dados diários de Londrina. Disponível em:

$<$ http://www.iapar.br/modules/conteudo/conteudo.php?conteudo=1828>. Acesso em: 24 de nov. 2014

MELO, Ângela Cristina Alves de. Resíduos Sólidos Domiciliares na Cidade de Rolândia-PR.: Coleta seletiva e reaproveitamento - reciclagem. 1999. Monografia de Conclusão de Curso Departamento de Geociências/CCE, Universidade Estadual de Londrina, 1999.

MILANI, E. J. Evolução tectono-estratigráfica da Bacia do Paraná e seu relacionamento com a geodinâmica fanerozóica do Gondwana Sul-Ocidental. 2 v. Tese (Doutorado) - Instituto de Geociências. Universidade Federal do Rio Grande do Sul, Porto Alegre, 1997. 
SANTOS, Maurício M. Avaliação do aquífero freático a jusante de um antigo depósito de resíduos em Rolândia-Pr. Trabalho de conclusão de curso (Bacharelado em Geografia) Departamento de Geografia, Universidade Estadual de Londrina, Londrina, 2003.

SILVA, Gabriela F. Avaliação Hidrogeológica e Implicações Hidroquímicas na Área de Entorno de um Antigo Lixão no Município de Rolândia - PR. Trabalho de Conclusão de Curso - Curso de Engenharia Ambiental, Universidade Tecnológica Federal do Paraná, Londrina, 2014.

YOSHIURA, Wilson. Análise Ambiental Preliminar da Porção Inferior da Bacia Hidrográfica do Ribeirão Três Bocas em Londrina - PR. 2006. Monografia de Conclusão de Curso - Curso de Geografia, Universidade Estadual de Londrina, Londrina, 2006. Disponível em:

$<$ http://www.uel.br/cce/geo/tcc/045_analiseambientalpreliminardaporcaoinferiordabaciahidrografica doribeiraotresbocasemlondrinapr_2006.pdf.pdf $>$. Acesso em: 11 de junho de 2016. 